\title{
FBI investigates radiation exposure claims
}

Washington. The Federal Bureau of Investigation (FBI) has launched a criminal investigation into the circumstances under which 27 researchers at the National Cancer Institute in Bethesda, Maryland, including a pregnant research fellow, were contaminated - apparently deliberately - with the radioisotope phosphorus-32.

The US Nuclear Regulatory Commission (NRC) is simultaneously investigating complaints from the fellow, Maryann Wenling $\mathrm{Ma}$, and her husband and laboratory partner, Bill Wenling Zheng, that lax safety procedures at the National Institutes of Health (NIH) contributed to the contamination incident. Lynne Bernabei, one of Ma's three lawyers, says Ma plans to sue NIH for the emotional distress she believes the incident has caused her.

In late June and early July, 27 researchers at the NCI's Laboratory of Molecular Pharmacology, were found to have abnormally high concentrations of the radioisotope, after drinking from a bottled water dispenser. Ma claims to have received the highest dose by eating leftover food spiked with the radioisotope. Ma, who is on a visiting fellowship from China - she was chosen in 1994 as one of the top 100 outstanding Chi- nese young scientists of the year - was 17 weeks pregnant at the time.

The FBI has yet to issue a formal statement. The NIH has acknowledged that radiation contamination took place. But deputy director Ruth Kirchstein says that that the agency will put up a vigorous defence against any charges of negligence.

"According to leading experts in the treatment of exposures to radioactivity, there is no reason to believe that $\mathrm{Ma}$ has been injured or her pregnancy compromised by the amount of radioactivity to which she was exposed," says Kirchstein.

Ma alleges in her complaint to the NRC that unauthorized access to radioisotopes was not impossible. She claims radioactive materials were rarely locked where she worked. But the agency refuses to confirm or deny Ma's claims that food was deliberately spiked. In addition, it disputes Ma's assertion that she received a higher dose than other researchers, and believes Ma's estimates for contamination are inflated.

Ma claims she received close to 1,000 microcuries, 16-times the yearly limit recommended by the NRC for pregnant women. But the NIH says it stands by its calculations that each of the contaminated researchers received between 300 and 600 microcuries - below the annual occupational limit for radiation exposure. Tests conducted by the NRC showed she received between 740 and 820 microcuries. Ma suggests that the NIH's urine and blood collection procedures diluted the samples.

In her formal complaint to the NRC, Ma also suggests that her supervisor, John Weinstein, a researcher at NIH for the past two decades, tried to persuade her to have an abortion to avoid disrupting a project involving Ma and her husband. Ma adds, he "tried to convince us that since our experiments had involved radiation, the baby we expected would not be safe".

Ma also says that Weinstein convinced her not to tell the NIH Radiation Safety Branch that she was pregnant. The couple were deciding whether to inform the radiation branch of her condition when a routine check five days later revealed she had become contaminated, she says.

Weinstein has not been available for comment. But his lawyer, Morris Topf, said Weinstein "categorically denies" suggestions that he urged Ma to abort the baby, describing such charges as "preposterous, slanderous and incomprehensible". Adrianne Appel

\section{Spanish research ambitions may face spending squeeze}

Munich. Spain's science budget would increase by more than a quarter in the next four years under the third national research plan, approved last month by the government. The plan also proposes a shift in public spending from fundamental to applied research. But, given the pressures on public spending, many feel that its ambitious goals are unlikely to be met.

Following Spain's first national plan in 1988 , money spent on research has grown on average by 10 per cent a year, and the number of researchers has increased from 26,000 to 42,000 . The government has since backed away from such a high rate of increase; this year, for example, the science budget grew by only 6.4 per cent. Nevertheless, the new plan, which runs from 1996 to 1999, envisages a 28-per cent increase in state spending.

The research plan aims to raise national spending on research and development (R\&D) from 0.84 per cent of gross national product to 1 per cent. It admits, however, that reaching this target would require a 70 per cent increase in industry's investment, raising the proportion of total $R \& D$ costs carried by industry from 46 per cent to 53 per cent, the European average.

Enric Banda, the Spanish research minister, claims that the huge increase in state financing of research over the past eight years "has allowed our science to mature, so we are now ready to ask research to help industrial interests". Hence the increased emphasis on applied research. "All European countries have done this, and we have instituted only a slight and controlled change," he says.

The change will include introducing more national research programmes on applied themes, such as telecommunications, biotechnology and environmental technologies, coordinated between ministries, as well as programmes that require both academic and industrial partners. It was drawn up after detailed consultation with 500 experts from both the academic and industrial sectors,

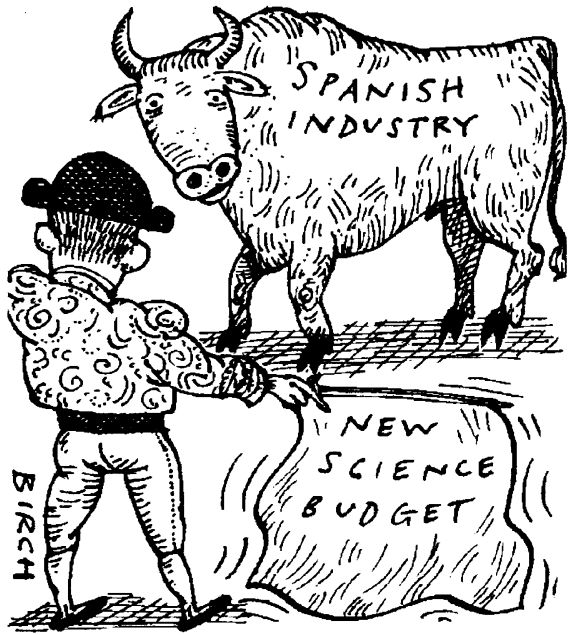

and has already found considerable support.

Pere Puigdomènech, for example, director of the Molecular Genetics Institute of the Consejo Superior de Investigaciones Cientificas (CSIC) in Barcelona, says that "it may be a good thing to have some more direction". But he adds that scientists are worried that Spanish industry, which does not have a strong research tradition, may not be able to participate as fully as the ministry hopes in the planned developments.

The government is also suffering from economic difficulties. Despite ambitious talk of growing budgets, the general Spanish budget proposal for 1996 does not meet the full increase in science funding suggested in the national plan.

Moreover, public funding for CSIC, which runs 87 research institutes but does not provide project money (which is allocated competitively from the research programmes of the national plan), is marked down for a three per cent cut under the 1996 Spanish budget proposal. This would prevent CSIC from carrying out any new building next year.

However, the 1996 budget appears unlikely to be passed, and the socialist government may be forced to resign as a result. Indeed, few scientists believe that the new government, whatever its political complexion, will be prepared to fully fund the national plan. 